\title{
MECANISMOS DE ABERTURA DO SULCO E ADUBAÇÃO NITROGENADA NO CULTIVO DO FEIJOEIRO EM SISTEMA PLANTIO DIRETO $\left({ }^{1}\right)$
}

\author{
ORIVALDO ARF (2*); RENATO JOSÉ AFONSO (2); AIRTON ROMANINI JUNIOR ( $\left.{ }^{2}\right)$; \\ MATHEUS GUSTAVO DA SILVA $\left({ }^{2}\right)$; SALATIER BUZETTI $\left({ }^{3}\right)$
}

\begin{abstract}
RESUMO
Algumas culturas têm pouca adaptação ao sistema plantio direto, em vista da maior compactação da camada superficial do solo e, nesse caso, o mecanismo utilizado na semeadora para a abertura dos sulcos para deposição do fertilizante pode ter grande importância no sentido de facilitar a penetração das raízes. Este experimento foi desenvolvido em Selvíria (MS), com o objetivo de avaliar a produtividade do feijão de inverno cultivado em sistema plantio direto, em função da utilização de mecanismos de abertura para distribuição de fertilizantes na semeadura e da adubação nitrogenada em cobertura. $O$ delineamento experimental utilizado foi em blocos casualizados, utilizando-se esquema fatorial $2 \times 6$, constituído por mecanismos de distribuição de fertilizante (haste escarificadora e disco duplo) e doses de $\mathrm{N}$ em cobertura $\left(0,25,50,75,100\right.$ e $\left.125 \mathrm{~kg} \mathrm{ha}^{-1}\right)$, com quatro repetições. Recomenda-se o uso da haste escarificadora como mecanismo de distribuição do fertilizante, para o cultivo do feijoeiro de inverno. A adubação nitrogenada em cobertura proporciona incrementos à produtividade do feijoeiro de inverno.
\end{abstract}

Palavras-chave: Phaseolus vulgaris L., plantio direto, disco duplo, haste escarificadora.

\section{ABSTRACT \\ FURROWS OPENING MECHANISM FOR NITROGEN FERTILIZER APPLICATION IN COMMON BEAN CROP UNDER NO-TILLAGE}

Some crops have shown no adaptation to no-tillage system as a function of compaction soil superficial layer. In way, the mechanism used in seeder to open furrows for deposition of fertilizer can have great importance to facilitate the penetration of roots. This experiment was carried in Selvíria (MS), with the objective to evaluate the winter common bean crop yield under no-tillage system, as function of fertilizer distribution opening mechanisms in sowing (chisel and coulter blade) and sidedressing nitrogen application $\left(0,25,50,75,100\right.$ and $\left.125 \mathrm{~kg} \mathrm{ha}^{-1}\right)$. The experimental design was a randomized block, arranged in a $2 \times 6$ factorial scheme, constituted by fertilizer distribution opening mechanisms in sowing (chisel and coulter blade) and sidedressing nitrogen doses $\left(0,25,50,75,100\right.$ and $125 \mathrm{~kg} \mathrm{ha}^{-1}$ ), with four replications. It is recommended the use of chisel as mechanism to open furrows for fertilizer deposition for the winter common bean crop cultivation. The sidedressing nitrogen application provides increment to the winter common bean crop yield.

Key words: Phaseolus vulgaris L., no-tillage, coulter blade, chisel, furrows.

$\left({ }^{1}\right)$ Recebido para publicação em 3 de outubro de 2006 e aceito em 23 de novembro de 2007.

$\left({ }^{2}\right)$ Departamento de Fitotecnia, Tecnologia de Alimentos e Sócio-Economia, FEIS/ UNESP - Campus de Ilha Solteira, Avenida Brasil, 56, Centro, 15385-000 Ilha Solteira (SP). E-mail: arf@agr.feis.unesp.br $\left(^{*}\right)$ Autor correspondente.

$\left({ }^{3}\right)$ Departamento de Fitossanidade, Engenharia Rural e Solos, FEIS/UNESP, Ilha Solteira (SP). 


\section{INTRODUÇÃO}

Um dos entraves do sistema plantio direto é a dificuldade que muitos produtores têm em adaptar corretamente as semeadoras-adubadoras para realizarem a semeadura direta, o que muitas vezes ocasionam imprevistos como a distribuição superficial do fertilizante no solo, em mistura com as sementes. Esse processo pode acarretar danos à germinação e também ao desenvolvimento superficial das raízes e, posteriormente, em profundidade, reduzindo assim o volume radicular, concorrendo para perdas de produtividade quando da ocorrência de estiagem (SIlva et al., 2000). Para que isso não ocorra é necessário que a semeadora-adubadora tenha mecanismos eficientes de corte dos restos culturais e distribuição do fertilizante, que proporcione sua colocação em profundidade adequada.

O uso da haste escarificadora propicia a colocação do adubo na linha do disco cortador e abaixo da semente, realizando pequeno preparo de solo na linha de semeadura, descompactando o solo na camada superficial. Entre as desvantagens estão a exigência de maior potência do trator, $20 \mathrm{a} 25 \mathrm{cv}$ a mais com oito linhas de semeadura, a incorporação de parte da palha por jogar terra em cima, o funcionamento irregular em solo úmido ou com palha espessa e tendência de deixar uma faixa sem palha sobre as linhas (LANDERS, 1995). O mesmo autor enfatiza que as culturas com melhores respostas são as seguintes: milho, feijão, girassol e algodão.

O efeito de dois mecanismos rompedores do solo e dois tipos de roda compactadora em semeadoraadubadora, no condicionamento físico do solo e no desenvolvimento de plantas de milho em semeadura direta, foi estudado por TAKAHASHI (2000), que verificou não haver diferença entre os tratamentos; porém, o rompedor tipo haste escarificadora permitiu aumento de $11 \%$ na produtividade, quando comparado ao mecanismo rompedor tipo disco duplo, sendo a produtividade maior em $714 \mathrm{~kg} \mathrm{ha}^{-1}$. O mecanismo rompedor tipo haste escarificadora foi mais eficiente no rompimento da camada superficial do solo, causando a diminuição da densidade e aumento da porosidade do solo, atenuando o problema de compactação e, o uso da roda compactadora em "V" permitiu a colocação das sementes em maiores profundidades.

Para a cultura do feijão, o N é o macronutriente absorvido em maiores quantidades e, pelo fato de aproximadamente $50 \%$ do $\mathrm{N}$ total absorvido ser translocado para os grãos, sua deficiência é a mais freqüente (Oliveira et al., 1996). Assim, segundo estes últimos autores, quando o $\mathrm{N}$ está deficiente, as plantas ficam atrofiadas, o caule e o ramo são delgados, e as folhas têm a coloração entre verde-pálido e amarela, o que pode ser corrigido com a aplicação de $\mathrm{N}$ em cobertura. Esse nutriente tem grande importância, principalmente nas fases de florescimento e enchimento de grãos, pois, como há vagens e grãos crescendo quase ao mesmo tempo, a demanda por $\mathrm{N}$ nessa fase é alta (PorTes, 1996). Trata-se de um nutriente que se perde facilmente por lixiviação, volatilização e desnitrificação, sendo seu manejo um dos mais difíceis. Para que a cultura expresse todo o seu potencial é necessário que o nutriente seja colocado no tempo e em local adequados. Diversos autores têm demonstrado que a adubação nitrogenada promove incrementos na produtividade de grãos do feijoeiro de inverno, em sistema plantio direto, utilizando-se doses de até $85 \mathrm{~kg}$ $\mathrm{ha}^{-1}$ de N (Silveira e DAMAsCeno, 1993; ChIDI et al., 2002; Bordin et al., 2003, Silva et al., 2004). Há ainda resultados em que o feijoeiro responde à adubação acima de $100 \mathrm{~kg} \mathrm{ha}^{-1}$ (BARBOSA FilHo e SILVA, 2000; STONE e Moreira, 2001; CarvalHo et al., 2003; SiLVA et al., 2003; MeIra et al., 2005).

Em função do exposto, acredita-se que o uso de haste escarificadora, por propiciar condições mais adequadas para o desenvolvimento do sistema radicular em profundidade, permita às plantas explorarem maior volume de solo, fazendo com que demandem maiores quantidades de nutrientes, incluindo o nitrogênio que é o elemento absorvido em maiores quantidades. Dessa forma, o objetivo deste experimento foi avaliar a produtividade do feijão de inverno cultivado em sistema plantio direto, em função da utilização de mecanismos de abertura do sulco para distribuição de fertilizantes na semeadura e de doses de $\mathrm{N}$ em cobertura.

\section{MATERIAL E MÉTODOS}

O experimento foi desenvolvido em área experimental pertencente à Faculdade de Engenharia - UNESP, Campus de Ilha Solteira, situada a 51 $22^{\prime}$ de longitude Oeste de Greenwich e $20^{\circ} 22^{\prime}$ de latitude Sul, com altitude de 335 metros, em Latossolo Vermelho distrófico típico argiloso (Embrapa, 1999). A precipitação pluvial média anual é de $1.370 \mathrm{~mm}$, a temperatura média anual é de $23,5{ }^{\circ} \mathrm{C}$ e a umidade relativa do ar está entre $70 \%$ e $80 \%$ (média anual).

Antes da instalação do experimento foram coletadas amostras de solo da área e realizada a análise química de acordo com método proposto por Raij e Quaggio (1983), com os seguintes resultados: $\mathrm{P}_{\text {resina }}=27 \mathrm{mg} \mathrm{dm}^{-3} ;$ M.O. $=19 \mathrm{~g} \mathrm{dm}^{-3} ; \mathrm{pH}\left(\mathrm{CaCl}_{2}\right)=$ 4,$7 ; \mathrm{K}, \mathrm{Ca}, \mathrm{Mg}, \mathrm{H}+\mathrm{Al}$ e CTC $=2,8 ; 25 ; 16 ; 43 ; 86 \mathrm{mmol}_{\mathrm{c}}$ $\mathrm{dm}^{-3}$ respectivamente, e $\mathrm{V}=51 \%$. A área estava em sistema plantio direto desde o ano agrícola 1996/1997. 
O delineamento experimental foi em blocos casualizados, em esquema fatorial com 12 tratamentos, constituídos pela combinação de dois mecanismos de abertura do sulco para a distribuição do adubo na semeadura (disco duplo e haste escarificadora) e doses de $\mathrm{N}(0,25,50,75,100$ e 125 $\mathrm{kg} \mathrm{ha}^{-1}$ ) em cobertura no sistema plantio direto, com quatro repetições. As parcelas foram constituídas por 5 linhas de $6,0 \mathrm{~m}$ de comprimento, espaçadas $0,50 \mathrm{~m}$ entre si. A área útil constituiu-se de 3 linhas centrais, desprezando as linhas externas e $0,50 \mathrm{~m}$ em ambas as extremidades de cada linha.

A adubação básica nos sulcos de semeadura foi de $250 \mathrm{~kg} \mathrm{ha}^{-1}$ da fórmula 04-30-10 + 0,3\% de Zn, calculada de acordo com as características químicas do solo e levando-se em consideração as recomendações de Ambrosano et al. (1996). A semeadura foi realizada em 4 de maio de 2004 e 31 de maio de 2005, utilizando a cultivar Pérola (plantas do tipo III e grãos do tipo carioca). Utilizou-se número de sementes necessário para obter 12 a 13 plantas $\mathrm{m}^{-}$ 1 , as sementes foram tratadas com carboxin + thiram (200 g + $200 \mathrm{~g}$ do i.a. para cada $100 \mathrm{~kg}$ de sementes) pouco antes da semeadura. Em ambos os anos, a adubação nitrogenada em cobertura foi realizada 15 dias após a emergência das plantas, utilizando-se uréia e irrigando posteriormente.

A precipitação pluvial foi determinada em um pluviômetro Ville de Paris instalado na área experimental. Para o manejo de água da cultura foram utilizados coeficientes de cultura $(\mathrm{Kc})$ das fases de desenvolvimento: germinação - folhas primárias $\left(\mathrm{V}_{0}\right.$ $\mathrm{V}_{2}=0,30$ ), primeira folha trifoliada - terceira folha trifoliada $\left(\mathrm{V}_{3}-\mathrm{V}_{4}=0,70\right)$, pré-floração - formação de vagens $\left(R_{5}-R_{7}=1,05\right)$, enchimento de vagens $\left(R_{8}=\right.$ $0,75)$ e maturação $\left(R_{9}=0,25\right)$ (Fernandez et al., 1986).

O controle de plantas daninhas foi realizado com a utilização de herbicidas. A dessecação da cobertura do solo foi feita com glyphosate (1560 $\mathrm{g}$ ha' ${ }^{1}$ do i.a.). As plantas daninhas que surgiram durante o desenvolvimento da cultura foram controladas, aos 16 e 18 dias após a emergência, com o herbicida fluazifop-p-butil+fomesafen $\left(200+250 \mathrm{~g} \mathrm{ha}^{-1}\right.$ do i.a. $)$, no primeiro ano de cultivo e fomesafen $\left(250 \mathrm{~g} \mathrm{ha}^{-1} \mathrm{do}\right.$ i.a.) no segundo ano respectivamente.

Durante o desenvolvimento da cultura do feijão foram realizadas as seguintes avaliações:

\section{Florescimento pleno e ciclo}

Foi avaliado o número de dias transcorridos entre a emergência e o florescimento pleno, ou seja, quando $50 \%$ das plantas estavam com a primeira flor aberta, com o objetivo de determinar o momento de avaliar a produção de massa seca de plantas e teor de $\mathrm{N}$ nas folhas.

\section{Produção de massa seca de plantas}

Por ocasião do florescimento pleno das plantas de feijão, foram coletadas em local predeterminado na área útil de cada parcela, 10 plantas que foram acondicionadas em saco de papel e levadas ao laboratório para secagem em estufa de ventilação forçada à temperatura média de 60 a $70^{\circ} \mathrm{C}$, até atingir massa constante.

\section{Teor de $\mathbf{N}$ nas folhas}

Para avaliar o teor de $\mathrm{N}$ nas folhas, foram utilizadas as $3 .{ }^{\text {as }}$ folhas com pecíolo, do terço médio da planta, amostradas no florescimento (AMBROSANO et al., 1997). As folhas não lavadas foram colocadas para secagem em estufa com circulação forçada de ar de 60 a $70^{\circ} \mathrm{C}$, por 72 horas, sendo em seguida moídas em moinho tipo Wiley. A quantidade acumulada de $\mathrm{N}$ foi quantificada segundo o método descrito por Malavolta et al. (1997).

\section{População de plantas}

Respectivamente na fase inicial de desenvolvimento e por ocasião da colheita, foram avaliadas as populações inicial e final de plantas de feijão por meio da contagem das plantas em duas linhas de $5 \mathrm{~m}$ na área útil das parcelas.

\section{Componentes de produção}

Por ocasião da colheita foram coletadas 10 plantas, em local predeterminado, na área útil de cada parcela e levadas para o laboratório para determinação de: a) Número de vagens por planta: obtido da relação número total de vagens/número total de plantas; $\mathbf{b}$ ) Número de grãos por planta: obtido da relação número total de grãos/número total de plantas; c) Número de grãos por vagem: obtido da relação número total de grãos/número total de vagens; d) Massa de cem grãos: obtida por meio da coleta ao acaso e pesagem de duas amostras de cem grãos por parcela.

\section{Produtividade de grãos}

$\mathrm{Na}$ colheita, foram coletadas duas linhas de $5 \mathrm{~m}$ dentro da área útil de cada parcela. Estas foram arrancadas e deixadas para secagem a pleno sol e depois submetidas à trilha mecânica, sendo os grãos pesados e os dados transformados em kg ha- ${ }^{-1}(13 \%$ base úmida). 


\section{RESULTADOS E DISCUSSÃO}

A emergência das plantas ocorreu de maneira uniforme, seis dias após a semeadura em ambos os anos de cultivo do experimento. $\mathrm{O}$ florescimento pleno foi registrado aos 49 e 50 dias após a emergência, com ciclo de 85 e 91 dias entre a semeadura e a colheita, respectivamente, para o cultivo em 2004 e 2005.

Os valores médios obtidos na avaliação do número de plantas referentes à população inicial e final e a produção de massa seca de plantas estão apresentados na Tabela 1. Verifica-se que para a população de plantas houve diferenças significativas entre os mecanismos de abertura dos sulcos para deposição do fertilizante, com o tratamento haste escarificadora proporcionando os maiores valores, tanto a população inicial como a final, nos dois anos de cultivo. É provável que o uso da haste escarificadora tenha permitido melhor distribuição do fertilizante em profundidade em relação ao disco duplo, mantendo, portanto uma distância maior entre o local de deposição do fertilizante e das sementes, minimizando a possibilidade de danos por efeito salino nas sementes, o que ocasionaria redução na população de plantas. As doses de $\mathrm{N}$ aplicadas em cobertura não influenciaram nos números de população inicial e final de plantas, nos dois anos de cultivo do experimento.

A massa seca de plantas não foi influenciada pelos dois mecanismos de abertura do sulco para deposição do fertilizante nos dois anos de cultivo. Já a aplicação de $\mathrm{N}$ em cobertura, no segundo ano de manejo do experimento, proporcionou ajuste dos dados obtidos à uma função linear crescente $(y=6,0704+0,0070 x)$, ou seja, houve aumento da produção de massa seca de plantas em função da utilização de doses crescentes de $\mathrm{N}$ em cobertura, na medida de 0,007 $\mathrm{g} /$ planta de massa seca para cada kg de $\mathrm{N}$ aplicado. Esse fato reforça a idéia da importância do $\mathrm{N}$, que por se tratar de constituinte da molécula de clorofila, tem influência na fotossíntese e promove o crescimento vegetativo do feijoeiro (Silveira e Damasceno, 1993).

Tabela 1. Valores de população inicial e final e massa seca de plantas de feijão em função de mecanismos de distribuição do fertilizante e doses de N em cobertura. Selvíria (MS), 2004 e 2005

\begin{tabular}{|c|c|c|c|c|c|c|}
\hline \multirow{2}{*}{ Tratamentos } & \multicolumn{2}{|c|}{ População inicial } & \multicolumn{2}{|c|}{ População final } & \multicolumn{2}{|c|}{ Massa seca de plantas } \\
\hline & 2004 & 2005 & 2004 & 2005 & 2004 & 2005 \\
\hline
\end{tabular}

Mecanismos de distribuição do fertilizante

$\begin{array}{lllllll}\text { Disco duplo } & 191.250 \mathrm{~b} & 204.167 \mathrm{~b} & 186.500 \mathrm{~b} & 181.250 \mathrm{~b} & 5,2 & 6,5 \\ \text { H. escarificadora } & 227.750 \mathrm{a} & 222.292 \mathrm{a} & 221.166 \mathrm{a} & 195.557 \mathrm{a} & 5,0 & 6,4\end{array}$

\begin{tabular}{|c|c|c|c|c|c|c|}
\hline \multirow[b]{2}{*}{0} & \multirow[b]{2}{*}{218.250} & \multicolumn{4}{|c|}{ Doses de $N\left(\mathrm{~kg} \mathrm{ha}^{-1}\right)$} & \multirow[b]{2}{*}{$5,7\left(^{1}\right)$} \\
\hline & & 218.750 & 212.750 & 187.488 & 5,1 & \\
\hline 25 & 217.250 & 215.000 & 211.250 & 183.437 & 4,7 & 6,9 \\
\hline 50 & 198.000 & 214.375 & 190.000 & 185.000 & 5,6 & 6,6 \\
\hline 75 & 206.500 & 211.875 & 205.250 & 195.000 & 5,2 & 6,3 \\
\hline 100 & 206.750 & 206.875 & 203.750 & 192.188 & 5,4 & 6,3 \\
\hline 125 & 210.250 & 212.500 & 200.000 & 187.187 & 4,5 & 7,2 \\
\hline$\overline{\text { Mecanismos (M) }}$ & $21,3^{* *}$ & $18,3^{* *}$ & $17,9^{* *}$ & $23,1^{* *}$ & $0,1^{\mathrm{ns}}$ & $0,1^{\mathrm{ns}}$ \\
\hline Doses (D) & $0,6^{\mathrm{ns}}$ & $0,6^{\mathrm{ns}}$ & $0,7^{\mathrm{ns}}$ & $1,5^{\mathrm{ns}}$ & $0,4^{\mathrm{ns}}$ & $2,2^{\mathrm{ns}}$ \\
\hline $\mathrm{F} \quad \mathrm{M} \times \mathrm{D}$ & $0,5^{\mathrm{ns}}$ & $0,2^{\mathrm{ns}}$ & $0,2^{\mathrm{ns}}$ & $2,2^{\mathrm{ns}}$ & $0,3^{\mathrm{ns}}$ & $0,2^{\mathrm{ns}}$ \\
\hline Dose de $R L$ & $0,6^{\mathrm{ns}}$ & $1,8^{\mathrm{ns}}$ & $0,7^{\mathrm{ns}}$ & $1,3^{\mathrm{ns}}$ & $0,1^{\mathrm{ns}}$ & $4,6^{*}$ \\
\hline $\mathrm{N} \quad \mathrm{RQ}$ & $1,3^{\mathrm{ns}}$ & $0,4^{\mathrm{ns}}$ & $0,5^{\mathrm{ns}}$ & $0,5^{\mathrm{ns}}$ & $0,6^{\mathrm{ns}}$ & $0,1^{\mathrm{ns}}$ \\
\hline DMS Mecanismos & 16,1 & 8,6 & 16,7 & 6,0 & - & - \\
\hline C.V. $(\%)$ & 13,1 & 6,9 & 13,9 & 5,5 & 37,4 & 14,9 \\
\hline
\end{tabular}

$\left({ }^{1}\right) \mathrm{y}=6,0704+0,0070 \mathrm{x}$

n.s. - não significativo

* e ** - significativo a 5 e $1 \%$ de probabilidade pelo teste $\mathrm{F}$ respectivamente.

Médias seguidas de mesma letra não diferem entre si pelo teste de Tukey a $5 \%$ de probabilidade. 
Os valores médios obtidos para teor de $\mathrm{N}$ nas folhas, número de grãos e vagens por planta estão relacionados na tabela 2 . O teor de $\mathrm{N}$ nas folhas, avaliado por ocasião do florescimento pleno, não foi influenciado pelos mecanismos de abertura dos sulcos para distribuição do fertilizante, nem mesmo pelas doses de $\mathrm{N}$ aplicadas em cobertura, nos dois anos de cultivo. Os valores obtidos em praticamente todos os tratamentos, no primeiro ano, estão dentro da faixa de 30 a $50 \mathrm{~g} \mathrm{~kg}^{-1}$, preconizada por AMBROSANo et al. (1997) e MALAVOLTA et al. (1997), como adequadas para o feijoeiro. Já no segundo ano, os valores obtidos em todos os tratamentos estão pouco abaixo da faixa indicada pelos autores, talvez devido à maior produção de massa seca de plantas neste ano, conforme observado na tabela 1.

Quanto ao número de vagens e de grãos por planta verifica-se que não houve efeito dos mecanismos de abertura do sulco para deposição do fertilizante. Por outro lado, houve aumento para esses dois componentes de produção em função da aplicação de doses crescentes de $\mathrm{N}$ em cobertura e os dados se ajustaram às funções lineares: $\mathrm{y}=6,2613+$ $0,0154 x$ (ano 2004) e y $=10,5374+0,0186 x$ (ano 2005), e y $=28,5303+0,08171 x($ ano 2004$)$ e $y=51,1780+$ $0,1123 x$ (ano 2005), respectivamente, para o número de vagens e de grãos por planta.

Os valores médios obtidos na avaliação do número de grãos por vagem, massa de cem grãos e produtividade de grãos estão relacionados na Tabela 3. O número de grãos por vagem e a massa de cem grãos não foram influenciados pelos mecanismos de abertura dos sulcos para distribuição do fertilizante, nem mesmo pelas doses de $\mathrm{N}$ aplicadas em cobertura nos dois anos de cultivo. Esses dois componentes estão mais relacionados com a característica genética da cultivar utilizada e são pouco influenciados pelas práticas culturais aplicadas. entretanto para o primeiro componente estudado (grãos por vagem), há relato de que a adubação nitrogenada poderia aumentar o número de óvulos fertilizados por vagem (Arf et al., 2004).

Tabela 2. Teor de $\mathrm{N}$ nas folhas $\left(\mathrm{g} \mathrm{kg}^{-1}\right)$ e de número de vagens e grãos por planta de feijão em função de mecanismos de distribuição do fertilizante e doses de N em cobertura. Selvíria (MS), 2004 e 2005

\begin{tabular}{|c|c|c|c|c|c|c|}
\hline \multirow{2}{*}{ Tratamentos } & \multicolumn{2}{|c|}{ Teor de $\mathrm{N}$ nas folhas } & \multicolumn{2}{|c|}{ Número de vagens planta ${ }^{-1}$} & \multicolumn{2}{|c|}{ Número de grãos planta ${ }^{-1}$} \\
\hline & 2004 & 2005 & 2004 & 2005 & 2004 & 2005 \\
\hline
\end{tabular}

Mecanismos de distribuição do fertilizante

\begin{tabular}{lllllll} 
Disco duplo & 31,5 & 26,2 & 6,8 & 12,2 & 31,5 & 55,2 \\
H. escarificadora & 32,2 & 25,5 & 7,7 & 11,2 & 35,8 & 61,2 \\
\hline
\end{tabular}

\begin{tabular}{|c|c|c|c|c|c|c|}
\hline H. escarificadora & 32,2 & 25,5 & 7,7 & 11,2 & 35,8 & 61,2 \\
\hline & \multicolumn{6}{|c|}{ Doses de $N\left(\mathrm{~kg} \mathrm{ha}^{-1}\right)$} \\
\hline 0 & 32,6 & 26,0 & $6,3^{1}$ & $10,1^{2}$ & $28,5^{3}$ & $50,4^{4}$ \\
\hline 25 & 29,1 & 24,9 & 6,6 & 11,6 & 30,6 & 55,6 \\
\hline 50 & 32,7 & 25,1 & 7,0 & 10,4 & 32,6 & 49,9 \\
\hline 75 & 32,0 & 24,2 & 7,4 & 13,1 & 34,7 & 67,9 \\
\hline 100 & 31,1 & 25,7 & 7,8 & 12,7 & 36,7 & 63,9 \\
\hline 125 & 33,6 & 29,2 & 8,2 & 12,2 & 38,7 & 61,5 \\
\hline Mecanismos (M) & $0,3^{\mathrm{ns}}$ & $0,2^{\mathrm{ns}}$ & $2,4^{\mathrm{ns}}$ & $1,6^{\mathrm{ns}}$ & $1,7^{\mathrm{ns}}$ & $2,0^{\mathrm{ns}}$ \\
\hline Doses (D) & $1,3^{\mathrm{ns}}$ & $0,9^{\mathrm{ns}}$ & $1,7^{\mathrm{ns}}$ & $1,6^{\mathrm{ns}}$ & $1,4^{\mathrm{ns}}$ & $2,0^{\mathrm{ns}}$ \\
\hline $\mathrm{F} \quad \mathrm{M} \times \mathrm{D}$ & $0,5^{\mathrm{ns}}$ & $1,9^{\mathrm{ns}}$ & $0,8^{\mathrm{ns}}$ & $1,1^{\mathrm{ns}}$ & $0,7^{\mathrm{ns}}$ & $1,2^{\mathrm{ns}}$ \\
\hline Doses de $R L$ & $0,7^{\mathrm{ns}}$ & $1,3^{\mathrm{ns}}$ & $5,3^{*}$ & $4,0^{*}$ & $4,6^{*}$ & $5,0^{*}$ \\
\hline $\mathrm{N} \quad \mathrm{RQ}$ & $0,8^{\mathrm{ns}}$ & $2,8^{\mathrm{ns}}$ & $0,2^{\mathrm{ns}}$ & $0,6^{\mathrm{ns}}$ & $1,2^{\mathrm{ns}}$ & $0,4^{\mathrm{ns}}$ \\
\hline
\end{tabular}

DMS Mecanismos

C.V. (\%)

12,5

20,1

27,6

23,5

33,5

25,5

$\left({ }^{1}\right) \mathrm{y}=6,2613+0,0154 \mathrm{x} \cdot\left({ }^{2}\right) \mathrm{y}=10,5374+0,0186 x \cdot\left({ }^{3}\right) \mathrm{y}=28,5303+0,0817 x \cdot\left({ }^{4}\right) \mathrm{y}=51,1780+0,1123 \mathrm{x}$ n.s.=- não significativo.

${ }^{*} \mathrm{e}^{* *}=-$ significativo a $5 \%$ e $1 \%$ de probabilidade pelo teste $\mathrm{F}$ respectivamente.

Médias seguidas de mesma letra não diferem entre si pelo teste de Tukey a $5 \%$ de probabilidade. 
Quanto à massa de cem grãos, em condições boas de cultivo, dificilmente se observará alteração significativa em seus valores, decorrentes da utilização de técnicas de manejo do solo e/ou adubação. Normalmente, as alterações promovidas sobre este componente se relaciona mais com a cultivar e, neste experimento, durante os dois anos, foi utilizada a mesma cultivar.

Para a produtividade de grãos, verifica-se que houve efeito dos mecanismos de distribuição do fertilizante, em que o tratamento com uso de haste escarificadora possibilitou a obtenção de produtividade mais elevada, $2.052 \mathrm{~kg} \mathrm{ha}^{-1} \mathrm{em} 2004 \mathrm{e}$ $1.817 \mathrm{~kg} \mathrm{ha}^{-1}$ em 2005 em relação à utilização do disco duplo (1.824 e $\left.1.693 \mathrm{~kg} \mathrm{ha}^{-1}\right)$, diferenças de 228 e 124 $\mathrm{kg} \mathrm{ha}^{-1}$, ou seja, um incremento de $12,5 \%$ e $7,3 \%$ na produtividade de grãos, respectivamente, para 2004 e 2005. É provável que a maior população de plantas obtida nesse tratamento tenha sido a causa principal do aumento de produtividade, uma vez que não foram identificadas diferenças no número de vagens e de grãos/planta, número de grãos/vagem e massa de cem grãos, entre os dois mecanismos de abertura de sulco para deposição do fertilizante. Os resultados discordam daqueles constatados por Pelissaro (2003), que, utilizando os mesmos mecanismos de abertura de sulco utilizado no presente experimento não obteve diferenças entre os dois mecanismos na produtividade de grãos do feijoeiro cultivado no período de inverno em sistema plantio direto.

Quanto à adubação nitrogenada em cobertura, observa-se que não houve diferenças entre as doses utilizadas em relação à produtividade de grãos no primeiro ano de cultivo (2004), estando em consonância com os resultados de FERrEIRA (1998), que também não observou efeito de doses de $\mathrm{N}$ nos componentes de produção e produtividade do feijoeiro cultivado no período de inverno. A falta de resposta à aplicação de $\mathrm{N}$ em cobertura, deve-se, provavelmente, ao fornecimento do nutriente pelo solo, aliado à fixação do $\mathrm{N}$ do ar atmosférico por bactérias nativas; embora não tenha sido realizada a inoculação de sementes, verificou-se a presença de nódulos no sistema radicular das plantas de feijão, visto que na cultivar utilizada observa-se, em campo, boa capacidade de nodulação.

Tabela 3. Número de grãos por vagem, massa de cem grãos (g) e produtividade de grãos do feijoeiro (kg ha-1) em função de mecanismos de distribuição do fertilizante e doses de N em cobertura. Selvíria (MS), 2004 e 2005.

\begin{tabular}{|c|c|c|c|c|c|c|}
\hline \multirow{2}{*}{ Tratamentos } & \multicolumn{2}{|c|}{ Número de grãos vagens ${ }^{-1}$} & \multicolumn{2}{|c|}{ Massa de cem grãos } & \multicolumn{2}{|c|}{ Produtividade de grãos } \\
\hline & 2004 & 2005 & 2004 & 2005 & 2004 & 2005 \\
\hline
\end{tabular}

Mecanismos de distribuição do fertilizante

\begin{tabular}{|c|c|c|c|c|c|c|}
\hline Disco duplo & 4,6 & 4,9 & 28,6 & 22,9 & $1.824 \mathrm{~b}$ & $1.693 \mathrm{~b}$ \\
\hline H. escarificadora & 4,6 & 5,0 & 29,0 & 23,0 & $2.052 \mathrm{a}$ & $1.817 \mathrm{a}$ \\
\hline \multicolumn{7}{|c|}{ Doses de N (kg ha $\left.{ }^{-1}\right)$} \\
\hline 0 & 4,6 & 4,9 & 29,2 & 23,2 & 1.906 & $1.333\left({ }^{1}\right)$ \\
\hline 25 & 4,5 & 4,8 & 29,5 & 22,7 & 1.967 & 1.590 \\
\hline 50 & 4,6 & 4,8 & 28,7 & 22,8 & 1.983 & 1.687 \\
\hline 75 & 4,7 & 5,2 & 28,3 & 23,0 & 1.828 & 1.992 \\
\hline 100 & 4,7 & 5,0 & 28,3 & 22,9 & 2.059 & 1.800 \\
\hline 125 & 4,6 & 5,1 & 28,7 & 23,2 & 1.875 & 2.129 \\
\hline Mecanismos (M) & $0,1^{\mathrm{ns}}$ & $0,8^{\mathrm{ns}}$ & $0,9^{\mathrm{ns}}$ & $0,1^{\mathrm{ns}}$ & $5,8^{*}$ & $9,0^{* *}$ \\
\hline Doses (D) & $0,1^{\mathrm{ns}}$ & $1,4^{\mathrm{ns}}$ & $1,3^{\mathrm{ns}}$ & $0,6^{\mathrm{ns}}$ & $0,5^{\mathrm{ns}}$ & $32,0^{* *}$ \\
\hline $\mathrm{F} \quad \mathrm{M} \times \mathrm{D}$ & $1,1^{\mathrm{ns}}$ & $1,3^{\mathrm{ns}}$ & $0,5^{\mathrm{ns}}$ & $0,9^{\mathrm{ns}}$ & $0,1^{\mathrm{ns}}$ & $1,4^{\mathrm{ns}}$ \\
\hline Doses de RL & $0,2^{\mathrm{ns}}$ & $2,7^{\mathrm{ns}}$ & $3,3^{\mathrm{ns}}$ & $0,1^{\mathrm{ns}}$ & $0,1^{\mathrm{ns}}$ & $35,4^{* *}$ \\
\hline $\mathrm{N} \quad \mathrm{RQ}$ & $0,1^{\mathrm{ns}}$ & $0,1^{\mathrm{ns}}$ & $1,0^{\mathrm{ns}}$ & $1,7^{\mathrm{ns}}$ & $0,1^{\mathrm{ns}}$ & 2,9 \\
\hline DMS Mecanismos & - & - & - & - & 195,4 & 84,1 \\
\hline C.V. $(\%)$ & 11,1 & 7,9 & 4,1 & 3,4 & 17,2 & 8,2 \\
\hline
\end{tabular}

$\left({ }^{1}\right) \mathrm{y}=1.403,55+5,6241 \mathrm{x}$

n.s. - não significativo

* e** - significativo a $5 \%$ e $1 \%$ de probabilidade pelo teste $\mathrm{F}$ respectivamente.

Médias seguidas de mesma letra não diferem entre si pelo teste de Tukey a 5\% de probabilidade. 
Já no segundo ano (2005), houve diferença entre os tratamentos, e os dados se ajustaram à função linear $\mathrm{y}=1.405,55+5,6241 \mathrm{x}$, ou seja, houve aumento de 5,62 kg de grãos de feijoeiro para cada $\mathrm{kg}$ de $\mathrm{N}$ aplicado em cobertura; a dose de $125 \mathrm{~kg} \mathrm{ha}^{-1} \mathrm{de} \mathrm{N}$ em cobertura proporcionou incremento de $796 \mathrm{~kg} \mathrm{ha}^{-1} \mathrm{em}$ relação à testemunha sem aplicação, ou seja $57 \%$ de aumento na produtividade.

A resposta do feijoeiro no segundo ano está relacionada com o aumento no número de vagens por planta, uma vez que os dois se correlacionam positivamente (Meira et al., 2005). Os valores obtidos superam os observados por BUZETTI et al. (1992), que, em condições semelhantes, verificaram aumento de $4,33 \mathrm{~kg}$ de grãos de feijão para cada $\mathrm{kg}$ de $\mathrm{N}$ aplicado. Quanto ao incremento proporcionado pela aplicação de $\mathrm{N}$ em cobertura, este supera o observado por Pelissaro (2003), que, em condições semelhantes, verificou aumento de $16 \%$ na produtividade de grãos, com a aplicação de $125 \mathrm{~kg} \mathrm{ha}^{-1}$ de $\mathrm{N}$ em cobertura, em relação à testemunha sem aplicação.

\section{CONCLUSÕES}

1. Recomenda-se o uso da haste escarificadora como mecanismo de distribuição do fertilizante, para o cultivo do feijoeiro de inverno.

2. A adubação nitrogenada em cobertura proporciona incrementos à produtividade do feijoeiro de inverno.

\section{REFERÊNCIAS}

AMBROSANO, E.J.; WUTKE, E.B.; BULISANI, E.; CANTARELLA, H. Feijão. In: RAIJ, B. van, CANTARELLA, $H$. QUAGGIO, J.A., FURLANI, A.M.C. Recomendações de adubação e calagem para o Estado de São Paulo. 2.ed. Campinas: IAC, 1996. p.194-195. (Boletim Técnico 100)

AMBROSANO, E.J.; TANAKA, R.T.;MASCARENHAS, H.A.A.; RAIJ, B. van; QUAGGIO, J.A.; CANTARELLA, H. Leguminosas e oleaginosas. In: RAIJ, B. van; CANTARELA, H.; QUAGGIO, J.A.; FURLANI, A.M.C. (Ed.). Recomendações de adubação e calagem para o Estado de São Paulo. 2.ed.rev. Campinas: IAC, 1997. p.189-203. (Boletim técnico, 100)

ARF, O.; RODRIGUES, R.A.F.; SÁ, M.E.; BUZETTI, S.; NASCIMENTO, V. Manejo do solo, água e $\mathrm{N}$ no cultivo de feijão. Pesquisa Agropecuária Brasileira, Brasília, v.39, n.2, p.131-138, 2004.

BALBINO, L.C.; MOREIRA, J.A.A.; SILVA, J.G.; OLIVEIRA, E.F.; OLIVEIRA, I.P. Plantio direto. In: ARAUJO, R.S.; RAVA, C.A.; STONE, L.F.; ZIMMERMANN, M.J.O. Cultura do feijoeiro comum no Brasil. Piracicaba: Potafós, 1996. p.301-352.
BARBOSA FILHO, M.P.; SILVA, O.F. Adubação e calagem para o feijoeiro irrigado na região dos cerrados. Pesquisa Agropecuária Brasileira, Brasília, v.35, n.7, p.1317-1324, 2000.

BORDIN, L.; FARINELLI, R.; PENARIOL, F.G.; FORNASIERI FILHO, D. Sucessão de cultivo de feijão-arroz com doses de adubação nitrogenada após adubação verde, em semeadura direta. Bragantia, Campinas, v.62, n.3, p.417-428, 2003.

BUZETTI, S.; ROMEIRO, P.J.M.; ARF, O.;SÁ, M.E.; GUERREIRO NETO, G. Efeito da adubação nitrogenada no desenvolvimento do feijoeiro (Phaseolus vulgaris L.) cultivado em diferentes densidades. Cultura Agronômica, Ilha Solteira, v.1, n.1, p.1119, 1992.

CARVALHO, M.A.C.; FURLANI JUNIOR, E.; ARF, O.; SÁ, M.E.; PAULINO, H.B.; BUZETTI, S. Doses e épocas de aplicação de $\mathrm{Ne}$ teores foliares deste nutriente e de clorofila em feijoeiro. Revista Brasileira de Ciência do Solo, Viçosa, v.27, n.3, p.445-450, 2003.

CHIDI, S.N.; SORATTO, R.P.; SILVA, T.R.B.; ARF, O.; SÁ, M.E.; BUZETTI, S. N via foliar e em cobertura em feijoeiro irrigado. Acta Scientiarum: Agronomia, Maringá, v.24, n.5, p.1391-1395, 2002.

CORSINI, P.C.; FERRAUDO, A.S. Efeitos de sistemas de cultivo na densidade e macroporosidade do solo e no desenvolvimento radicular do milho em Latossolo Roxo. Pesquisa Agropecuária Brasileira, Brasília, v.34, n.2, p.289-298, 1999.

EMPRESA BRASILEIRA DE PESQUISA AGROPECUÁRIA. Sistema brasileiro de classificação de solos. Rio de Janeiro: EMBRAPA/CNPSO, 1999. 412p.

FERNANDEZ, F.; GEPTS, P.; LOPES, M. Etapas de desarrollo de la planta de frijol (Phaseolus vulgaris L.). Cali: Centro Internacional de Agricultura Tropical, 1986. 34p.

FERREIRA, E.C. Efeito de doses e parcelamento da adubação nitrogenada em cobertura na cultura do feijão (Phaseolus vulgaris L.). 1998. 31p. Monografia (Trabalho de Graduação) FE/UNESP, Ilha Solteira.

LANDERS, J.N. Fascículo de experiências de plantio direto no cerrado. Goiânia: A.P.D.C., 1995. 261p.

MALAVOLTA, E.; VITTI, G.C.; OLIVEIRA, S.A. (Ed.). Avaliação do estado nutricional de plantas: princípios e aplicações. 2.ed. Piracicaba: Potafos, 1997. 319p.

MEIRA, F.A.; SÁ, M.E.; BUZETTI, S.; ARF, O. Doses e épocas de aplicação de $\mathrm{N}$ no feijoeiro irrigado cultivado em plantio direto. Pesquisa Agropecuária Brasileira, Brasília, v.40, n.4, p.383-388, 2005.

OLIVEIRA, I.P.; ARAÚJO, R.S.; DUTRA, L.G. Nutrição mineral e fixação biológica de N. In: ARAÚJO, R.S.; RAVA, C.A.;STONE, L.F.; ZIMMERMANN, M.J.O. (Coords.). Cultura do feijoeiro comum no Brasil. Piracicaba: Potafós, 1996. p.169-221.

PELISSARO, D.S. Resposta do feijoeiro à mecanismos de abertura do sulco de semeadura para deposição do fertilizante e doses de $\mathbf{N}$ em cobertura. Ilha Solteira, 2003. 24p. Monografia (Trabalho de Graduação) - Faculdade de Engenharia, Universidade Estadual Paulista. 
PORTES, T.A. Ecofisiologia. In: ARAÚJO, R.S.; RAVA, C.A.; STONE, L.F.; ZIMMERMANN, M.J.O. (Coords.). Cultura do feijoeiro comum no Brasil. Piracicaba: Potafós, 1996. p.101-137.

RAIJ, B. van; QUAGGIO, J.A. Métodos de análises de solo para fins de fertilidade. Campinas: Instituto Agronômico, 1983. 31 p. (Boletim Técnico, n. 81)

SILVA, M.G.; ARF, O.; SÁ, M.E.; RODRIGUES, R.A.F.; BUZETTI, $S$. Nitrogen fertilization and soil management of winter common bean crop. Scientia Agricola, Piracicaba, v.61, n.3, p.307-312, 2004.

SILVA, T.R.B.; ARF, O.; SORATTO, R.P. Adubação nitrogenada e resíduos vegetais no desenvolvimento do feijoeiro em sistema plantio direto. Acta Scientiarum: Agronomia, Maringá, v.25, n.1, p.81-87, 2003.
SILVA, J.G.; KLUTHCOUSHI, J.; SILVEIRA, P.M. Desenvolvimento de uma semeadora-adubadora no estabelecimento e na produtividade da cultura do Milho sob plantio direto. Scientia Agricola, Piracicaba, v.57, n.1, p.7-12, 2000.

SILVEIRA, P.M.; DAMASCENO, M.A. Doses e parcelamento de $\mathrm{K}$ e de $\mathrm{N}$ na cultura do feijoeiro irrigado. Pesquisa Agropecuária Brasileira, Brasília, v.28, n.11, p.1269-1276, 1993.

STONE, L.F.; MOREIRA, J.A.A. Resposta do feijoeiro ao N em cobertura, sob diferentes lâminas de irrigação e preparos de solo. Pesquisa Agropecuária Brasileira, Brasília, v.36, n.3, p.473481, 2001.

TAKAHASHI, C.M. Mecanismos rompedores e rodas compactadoras de semeadora-adubadora para cultura do milho (Zea mays L.) em plantio direto. 2000, 47 p. Monografia (Trabalho de Graduação) - FE/UNESP, Ilha Solteira. 